\title{
Dynamic Instability of a Wind Turbine Blade Due to Large Deflections: An Experimental Validation
}

\author{
Andres Lopez-Lopez ${ }^{1}$ - Jose Billerman Robles-Ocampo ${ }^{2,}{ }^{*}$ - Perla Yazmin Sevilla-Camacho ${ }^{2}$ - \\ Orlando Lastres-Danguillecourt ${ }^{1}$ - Jesús Muniz ${ }^{3}$ - Bianca Yadira Perez-Sariñana ${ }^{2}$ - Sergio de la Cruz ${ }^{2}$ \\ 1 University of Sciences and Arts of Chiapas, Mexico \\ 2 Polytechnic University of Chiapas, Energy and Sustainability Academic Group, Mexico \\ 3 National Autonomous University of Mexico Renewable Energy Institute, Mexico
}

Wind turbine blades are designed to be thin and flexible elements. Because unstable dynamic behaviour can affect the life of the rotor, it is crucial to understand the instability of non-linear behaviour caused by large deflections. The present study undertakes both a stability analysis of the non-linear response and an experimental validation of a simplified model for a wind turbine blade based on a cantilever beam. The model is formulated taking into account large geometric deflections and assuming a Galerkin approach. The model is validated experimentally in a wind tunnel with aluminium beams of differing geometry. Analysis of the dynamic response using phase planes reveals that the degree of instability is related to the amplitude of the excitation and the stiffness characteristics.

Keywords: non-linear model, large deflection, wind turbine blade, phase planes, instability

Highlights

- $\quad$ Slenderness and wind speed are parameters that have a significant influence on the stability of the dynamic behaviour of large wind turbine blades.

- The non-linear dynamic model enables the dynamic behaviour of wind turbine blades to be obtained, taking into account the dynamic and gravitational loads.

- $\quad$ The phase planes enable the level of stability of the dynamic behaviour of HAWT blades to be detected qualitatively.

- The nonlinearity of the model is linked to the large deflections present in the blade.

\section{INTRODUCTION}

The strategy generally applied to obtain greater efficiency and increase the levels of power generated by a wind turbine involves the use of large diameter rotors and the manufacture of thinner, larger, lighter, and more flexible blades, resulting in a rotor diameter of $168 \mathrm{~m}$ [1]. However, new blade designs cause greater sensitivity to dynamic excitations, which reduce wind turbine life span and efficiency, and increased vibrations and large deflections; these cause a high level of rotor instability [2]. Furthermore, the blades are usually subject to random and complex mechanical stresses [3].

In dynamic wind turbine blade models, elastic deformation is often considered in four directions, including flapwise (out-plane) and edgewise (in-plane or lead/lag) transverse deflections as the two main directions of vibration, as well as axial (longitudinal) and torsional (feather) deformations. As the blade is sufficiently stiff in both a torsional and longitudinal direction, the deformation occurring in these directions can usually be ignored. Moreover, as the cross-section of the blade is designed to make it stiffer in an edgewise direction than in a flapwise direction
[4], researchers have focused more on studying the flapwise vibration of the blades [4] to [6].

Recent studies conducted on dynamic blade models in a flapwise direction include that of Jokar et al. [7], who used the Hamiltonian principle to derive a non-linear partial differential equation for a wind turbine blade. Although they did linearize and simplify the non-linear model to find natural frequencies, their model did not include the effect of large deformations. However, for modern large-scale slender and flexible blades, consideration must also be given to the deformation caused by external loads which, in many cases, results in a non-linear geometric effect on the blade. Both this effect and the aeroelastic effects of extreme wind conditions are becoming more and more common with the increasing flexibility of wind turbine blades. Using the multi-body method, $\mathrm{Xu}$ et al. [8] built a blade analysis model that describes the geometric nonlinearity and complex geometry of the blades, for which they obtained accurate results. They found that the accuracy of their results increased as the number of rigid bodies increases, although they also observed that the calculation time increases exponentially. 
Cruz et al. [9] presented the experimental validation of a simplified one-dimensional model of a cantilever beam formulated considering large geometric deformations and assuming a Galerkin approach. They aimed to ascertain the non-linear behaviour caused by the large deformations of thin structures, such as wind turbine blades. Onedimensional blade models have a low computational cost and have been used to efficiently model nonlinear vibration analysis for a wind turbine blade, for both in-plane [10] and out-plane motion [11]. These models consider the geometric nonlinearity of blades, namely that large deformations cause a significant change in force, with a non-linear relationship between force and displacement. Gerstmayr and Irschik [12] represented large deformations using the elastic line approach. They used a cubic polynomial to represent the displacement; a similar approach is also applied in the present work.

Maktouf et al. [13] undertook the modal and nonlinear dynamic analysis of a rotating wind turbine blade in order to study the effects of rotation speed on natural frequencies and displacements, finding that the natural frequencies and displacements of the blade increase when the angular rotation speed is increased. While the sensitivity of the blade's vibration characteristics to geometric nonlinearity was significant, the study did not consider aerodynamic effects.

Liu [14] studied the effect of the aerodynamic load and its interaction with the structure under uniformly distributed wind flow conditions, determining an expression for the wind force per unit based on both average and fluctuating wind speed. Additionally, researchers have used both blade element momentum (BEM) theory and actuator disk theory in the development of aeroelastic models [15] to [17]. Moreover, Akbiyik et al. [18] evaluated an air foil in a wind tunnel with a test section of $570 \mathrm{~mm} \times$ $570 \mathrm{~mm} \times 1000 \mathrm{~mm}$, measuring and monitoring the response signal using an oscilloscope.

While phase planes have been applied as a qualitative technique for analysing the dynamic stability of thin structures under considerable excitation amplitudes [19] and [20], phase planes should better pictorially represent the chaotic motion.

The present study seeks to evaluate the unstable response of wind turbine blades with large deflections, assuming maximum flapwise deflections in the presence of extreme wind loads and the blade tip at the highest part of the rotor. The model is based on a one-dimensional cantilever beam Lagrangian formulation that considers the following: uniform wind distribution, an effective blade surface normal to wind incidence; non-linear curvature of the beam and internal viscous damping. Also, an experimental set based on a wind tunnel is proposed for model validation.

The present research is of relevance for improving the design of wind turbine blades that present excessive vibrations and substantial deviations, as it provides an efficient tool for analysing the nonlinear response via phase planes. In addition, it offers a visual interpretation (qualitative behaviour) of the evolution of the instability under increasing wind speed. The main advantage of the method proposed is that, although it considers a similar shape to the blade and, solely deformation in a flapwise direction, the non-linear dynamic behaviour is described efficiently and with a low computational cost. Furthermore, the method determines the degree of blade stability in different conditions, ranging from low wind speeds to extreme loads.

\section{DYNAMIC MODEL}

\subsection{Description of the Dynamic System}

The blades undergo variable tension-compression stresses during one rotation of a wind turbine rotor. These stresses are caused by the combined loads of the gravity and dynamic pressure of the fluid on the structure. Moreover, they depend on the angular position of the blade in the plane of rotation, namely that the angular position of the blade changes during its rotation in the plane of rotation, which also causes the stresses to change from tension to compression during each rotation and vice versa. However, when the blade is positioned vertically, the tip reaches the highest part of the wind turbine. In this instantaneous angular position, the bending moments that act on the blade are at a maximum because their interactions with wind speeds are more intense and provoke large blade deflections. Within this time frame, the dynamic behaviour of the rotor is strongly influenced by the large blade deflections.

In contrast, the blade, which is joined to the wind turbine hub, resembles a cantilever beam. Under this analogy, the mathematical modelling for the blade is considered a thin blade rigidly embedded at one of its ends, which causes the other free end to bend laterally in the direction of the wind, as seen in Fig. 1. As the coordinate system $(x, y)$ is perpendicular to the plane of rotation $(x, z)$, the out-plane deflection is defined by $\xi(y)$, the slope of deflection by $\theta(y)$, and the normal force of the wind on the rotation plane as $F$. 


\subsection{Large Blade Deflections}

In the dynamic system proposed, the wind force is assumed to be perpendicular to the plane of rotation, while the displacements out-plane are determined to be parallel to the wind direction, and the rotational displacements and torsional deformations are considered null [7]. Thus, the movement of the blade in the coordinate plane $(x, y)$ is defined as one-dimensional and restricts the movement of the deflection $\xi(y)$.

For the continuous vibratory system, the deflection of the blade at any point along its length is determined by discretizing it into small onedimensional beam-type elements by means of finite element method (FEM). This discretization enables the deflection $\xi(y)$ to be defined as a function of the nodal displacements of each one-dimensional element, expressed in Eq. (1). $N_{i}(y)$ is called function form, while is nodal displacement and $\xi_{i}(y)$ is the number of discretization nodes [21].

$$
\xi(y)=\sum_{i=1}^{n} N_{i}(y) \xi_{i}(y) .
$$

The deflection of the blade is defined in Eq. (2) as a cubic polynomial dependent on the vertical position, where the coefficients $g_{i}$ relate the deflection $\xi(y)$ to $\theta(y)$ its slope [12].

$$
\xi(y)=g_{0}+g_{1} \frac{y}{L}+g_{2} \frac{y^{2}}{L^{2}}+g_{3} \frac{y^{3}}{L^{3}} .
$$

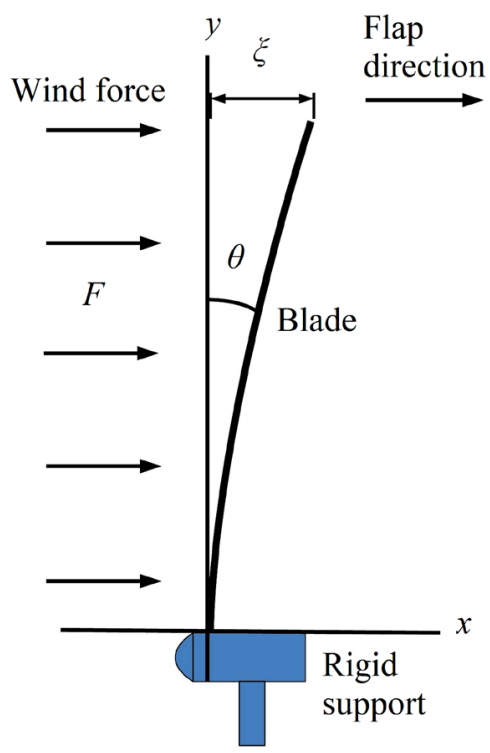

Fig. 1. Free body diagram of the lateral deflection of a wind turbine blade
The blade is discretized into two nodes corresponding to each of the ends of the beam. The displacements of the embedded node are defined by $\xi(0)$ and $\theta(0)$, while the displacements of the free node are defined by $\xi(L)$ and $\theta(L)$, respectively; moreover, the unknown displacements in the nodes must satisfy the following conditions:

$$
\begin{aligned}
& \xi(0)=\xi_{1}(y), \quad \frac{\partial \xi(0)}{\partial y}=\theta_{1}(y), \\
& \xi(L)=\xi_{2}(y), \quad \frac{\partial \xi(L)}{\partial y}=\theta_{2}(y) .
\end{aligned}
$$

The foregoing defines the coefficients of the cubic polynomial as:

$$
\begin{aligned}
& g_{0}=\xi_{1}(y), \\
& g_{1}=\theta_{1} L, \\
& g_{2}=3 \xi_{2}-3 \xi_{1}-2 \theta_{1} L-\theta_{2} L, \\
& g_{3}=\theta_{2} L+\theta_{1} L-2 \xi_{2}+2 \xi_{1} .
\end{aligned}
$$

Thus, substituting the coefficients from Eq. (4) into Eq. (2) obtains a general expression for the elastic curve.

$$
\begin{aligned}
\xi(y)= & \xi_{1}+\theta_{1} y+\frac{1}{L^{2}}\left(3 \xi_{2}-3 \xi_{1}-2 \theta_{1} L-\theta_{2} L\right) y^{2}+ \\
& +\frac{1}{L^{3}}\left(\theta_{2} L+\theta_{1} L-2 \xi_{2}+2 \xi_{1}\right) y^{3} .
\end{aligned}
$$

Because the lower end of the blade is embedded, neither lateral nor angular displacement, namely $\xi(0)=0$ and $\theta(0)=0$, is found; however, displacements on the free end are found and defined as $\xi(L)=\xi(y)$ and $\theta(L)=\theta(y)$. The deflection of the blade on any point of its length is governed by Eq. (6) in its simplified form.

$$
\xi(y)=N_{1} \xi+N_{2} \theta,
$$

where the function form $N_{1}$ and $N_{2}$ are described as:

$$
\begin{gathered}
N_{1}=\frac{3 y^{2}}{L^{2}}-\frac{2 y^{3}}{L^{3}}, \\
N_{2}=\frac{y^{3}}{L^{2}}-\frac{y^{2}}{L} .
\end{gathered}
$$

\subsection{Kinematics of the Blade Deflection}

This section defines the kinetic and potential energy of the movement of the blade out of the plane of rotation. Continuing with the analogy of the blade as a thin beam, the kinetic energy $T$ of its displacement will be defined by Eq. (9), where $\rho$ defines the density of the blade and $A$ the cross-section area of the profile [22]. 


$$
T=\frac{1}{2} \rho A \int_{0}^{L}\left(\frac{\partial \xi(y)}{\partial t}\right)^{2} d x .
$$

Substituting and solving Eq. (6) in (9) obtains an expression for the kinetic energy of the blade in a state of deflection.

$$
T=\frac{1}{2} \rho A L\left[\frac{1}{105} \dot{\theta}^{2} L^{2}-\frac{11}{105} L \dot{\theta} \dot{\xi}+\frac{13}{35} \dot{\xi}^{2}\right] .
$$

Given that no significant change in the vertical position of the blade occurs during its deflection, the gravitational potential energy is considered null. Thus, the potential energy of the dynamic system is determined solely by the lateral deformation of the blade.

\subsection{Potential Energy of Deformation}

Given that no significant change is found for the vertical position of the blade during its movement, the developed potential energy is attributed to the deformation energy. For a cantilevered thin beam, the deformation energy is specified in Eq. (11), where $k$ denominates the deflection curvature, $E$ the modulus of elasticity and $I$ the moment of inertia of the transversal section of the blade [9].

$$
U=\frac{E I}{2} \int_{0}^{L} k^{2} d y .
$$

For large deflections, the square of the deflection curvature $k$ given by [19], is approximate in the following manner:

$$
k^{2} \approx\left(\frac{\partial^{2} \xi(y)}{\partial y^{2}}\right)^{2}\left[1-\frac{3}{2}\left(\frac{\partial \xi(y)}{\partial y}\right)^{2}\right]^{2} .
$$

Solving Eq. (11) for large deflections, the potential energy of the blade, caused by its lateral deformation, is determined by:

$$
\begin{aligned}
U= & \frac{E I}{770 L^{7}}\left(648 \theta^{6} L^{6}-1044 \xi \theta^{5} L^{5}+270 \xi^{2} \theta^{4} L^{4}-\right. \\
& -1215 \xi^{3} \theta^{3} L^{3}+4050 \xi^{4} \theta^{2} L^{2}-6804 \xi^{5} \theta L+ \\
& +5832 \xi^{6}-1408 \theta^{4} L^{6}+2640 \xi \theta^{3} L^{5}- \\
& -2376 \xi^{2} \theta^{2} L^{4}+5940 \xi^{3} \theta L^{3}-7128 \xi^{4} L^{2}+ \\
& \left.+4620 \xi^{2} L^{4}-4620 \xi L^{5} \theta+1540 \theta^{2} L^{6}\right) .
\end{aligned}
$$

\subsection{Wind Excitation Force}

The wind causes a pressure increase on the pressure surface of the blades and a pressure decrease on the suction surface of the blades, with this pressure differential causing a laterally displaced axial force to be exerted on the blade. In accordance with Liu [14], the instant wind pressure $W(y, t)$ can be calculated as:

$$
W(y, t)=\bar{W}(y)+W_{j}(y, t),
$$

where the average wind pressure is $\bar{W}(y)=$ $\frac{1}{2} \rho_{W} \mu \bar{V}^{2}(y)$ and the fluctuating wind pressure is $W_{j}(y, t)=\frac{1}{2} \rho_{W} \mu \bar{V}_{j}^{2}(y, t)$, while $\mu$ is the shape coefficient, $\bar{V}(y)$ is the average wind speed, $\bar{V}_{j}^{2}(y, t)$ is the fluctuating wind speed, and $\rho_{W}$ is the air density.

Assuming uniform airflow without fluctuation, in Eq. (14), this is defined as:

$$
W(y)=\bar{W}(y)=\frac{1}{2} \rho_{W} \mu \bar{V}^{2}(y) .
$$

The airflow over the element can be simplified further to facilitate comprehensive analysis, considering wind force to be uniformly distributed along its entire length and expressed as the Dirac delta function, in Eq. (16), while $L$ is the blade length.

$$
F(y)=W(y) \delta(y-L) .
$$

Eqs. (17) and (18) determine the wind force in terms of the displacements $\xi(y)$ and $\theta(y)$.

$$
\begin{aligned}
& P_{\xi}=\int_{0}^{l} F(y) N_{1} d y, \\
& P_{\theta}=\int_{0}^{l} F(y) N_{2} d y .
\end{aligned}
$$

Evaluating the function, Eq. (16), in $y=L$, the Eqs. (19) and (20) are obtained. These equations describe the distribution of fluid over the blade.

$$
\begin{gathered}
P_{\xi}=F, \\
P_{\theta}=0 .
\end{gathered}
$$

\subsection{Structural Damping Forces}

The structural damping force of the blades is caused by the dissipation of energy that occurs during deflection. This energy is not derived from a potential function and depends on the deflection speed. The dissipative energy of the blade $E_{D}$ is modelled using Eq. (21), where $C$ is the structural damping coefficient [10].

$$
E_{D}=\frac{1}{2} C \dot{g}_{i}^{2}
$$

The Rayleigh function models the internal dissipation forces of bodies with viscous damping. 


$$
D=-\frac{\partial E_{D}}{\partial \dot{g}_{i}} .
$$

These structural damping forces are determined for $\xi(y)$ and $\theta(y)$, and, on solving Eqs. (23) and (24) [9].

$$
\begin{aligned}
& D_{\xi}=-C \int_{0}^{L}\left(\frac{\partial \xi(y)}{\partial t}\right) N_{1} d y, \\
& D_{\theta}=-C \int_{0}^{L}\left(\frac{\partial \xi(y)}{\partial t}\right) N_{2} d y .
\end{aligned}
$$

\subsection{Dynamic Modelling}

The dynamic modelling of the blade as a continuous vibratory system is obtained from the Lagrange movement equations, where the Lagrangian $\mathcal{L}$ is defined as the difference between the kinetic $T$ and potential $U$ energy of the blade deflection and the term $Q_{i}$ defines the forces not derived from a potential function. Variable $g_{i}$ represents the generalized coordinates $\xi(y)$ and $\theta(y)$ of the dynamic system [23].

$$
\frac{\partial}{\partial t}\left(\frac{\partial \mathcal{L}}{\partial \dot{g}_{i}}\right)-\frac{\partial \mathcal{L}}{\partial g_{i}}=Q_{i} .
$$

Finally, solving Eq. (25) in terms of $\xi(y)$ and $\theta(y)$ obtains the following system of differential equations, which model the non-linear dynamic behaviour of a wind turbine blade presenting large deflections:

$$
\begin{gathered}
\ddot{\xi}=\frac{12}{m} P_{\xi}+\frac{66}{m L} D_{\theta}+\frac{12}{m} D_{\xi}-\frac{12}{m} U_{\xi}-\frac{66}{m L} U_{\theta}, \\
\ddot{\theta}=-\frac{66}{m L} U_{\xi}+\frac{468}{m L^{2}} U_{\theta}+\frac{66}{m L} P_{\xi}+\frac{468}{m L^{2}} D_{\theta}+\frac{66}{m L} D_{\xi},
\end{gathered}
$$

where:

$$
\begin{aligned}
U_{\xi}= & \frac{E I}{770 L^{7}}\left(-1044 \theta^{5} L^{5}+540 \xi \theta^{4} L^{4}-3645 \xi^{2} \theta^{3} L^{3}+\right. \\
& +16200 \xi^{3} \theta^{2} L^{2}-34020 \xi^{4} \theta L+34992 \xi^{5}+ \\
& +2640 \theta^{3} L^{5}-4752 \xi \theta^{2} L^{4}+17820 \xi^{2} \theta L^{3}- \\
& \left.-28512 \xi^{3} L^{2}+9240 \xi L^{4}-4620 L^{5} \theta\right),
\end{aligned}
$$

and

$$
\begin{aligned}
U_{\theta}= & -\frac{E I}{770 L^{7}}\left(-3888 \theta^{5} L^{6}+5220 \xi \theta^{4} L^{5}-\right. \\
& -1080 \xi^{2} \theta^{3} L^{4}+3645 \xi^{3} \theta^{2} L^{3}-8100 \xi^{4} \theta L^{2}+ \\
& +6804 \xi^{5} L+5632 \theta^{3} L^{6}-7920 \xi \theta^{2} L^{5}+ \\
& +4752 \xi^{2} \theta L^{4}-5940 \xi^{3} L^{3}+4620 \xi L^{5}- \\
& \left.-3080 \theta L^{6}\right) .
\end{aligned}
$$

\section{NUMERICAL SIMULATION}

The Runge-Kutta $4^{\text {th }}$ order method is used to solve Eqs. (26) and (27). This method is limited to solving systems of first-degree differential equations, for which reason the following change of variables was carried out:

$$
Z=\dot{\xi}(y), \quad Y=\dot{\theta}(y), \quad \dot{Z}=\ddot{\xi}(y), \quad \dot{Y}=\ddot{\theta}(y) .
$$

Thus defining a system of first-degree differential equations:

$$
\left[\begin{array}{c}
\dot{\xi} \\
\dot{Z} \\
\dot{\theta} \\
\dot{Y}
\end{array}\right]=\left[\begin{array}{c}
Z \\
\frac{12}{m} P_{\xi}+\frac{66}{m L} D_{\theta}+\frac{12}{m} D_{\xi}-\frac{12}{m} U_{\xi}-\frac{66}{m L} U_{\theta} \\
Y \\
-\frac{66}{m L} U_{\xi}+\frac{468}{m L^{2}} U_{\theta}+\frac{66}{m L} P_{\xi}+\frac{468}{m L^{2}} D_{\theta}+\frac{66}{m L} D_{\xi}
\end{array}\right] .
$$

The dynamic model is compared to other models in the literature, with the fundamental frequencies obtained shown in Table 1, with a maximum error of $2.1 \%$.

Table 1. Comparison of fundamental frequencies

\begin{tabular}{lccc}
\hline Test & Ref. [9] [Hz] & Ref. [24] [Hz] & Ref. [25] [Hz] \\
\hline Comparative & 1.40 & 5.92 & 3.33 \\
\hline Model & 1.42 & 6.00 & 3.40 \\
\hline Error \% & 1.42 & 1.35 & 2.10 \\
\hline
\end{tabular}

Below, four blades are evaluated with the geometric characteristics and mechanical properties of aluminium beams shown in Table 2, in both free and forced movement and with wind speeds of $10 \mathrm{~m} / \mathrm{s}, 20$ $\mathrm{m} / \mathrm{s}$, and $30 \mathrm{~m} / \mathrm{s}$. The beams were selected based on network similarity [9], while the shape and dimension were chosen for later validation in a wind tunnel. The shape coefficient values given are approximate [26].

Table 2. Physical characteristics and mechanical properties of the simulation blades

\begin{tabular}{ccccc}
\cline { 1 - 3 }$E[\mathrm{GPa}]$ & $\rho\left[\mathrm{kg} / \mathrm{m}^{3}\right]$ & $\tau\left[\mathrm{E}^{-3} \mathrm{~m}\right]$ & $L[\mathrm{~m}]$ & \\
\cline { 1 - 4 } \multicolumn{1}{c}{270} & 2700 & 1.590 & 0.240 & \\
\cline { 1 - 4 } Blade & $S\left[\mathrm{~m}^{2}\right] \mathrm{E}^{-3}$ & $C[\mathrm{~kg} / \mathrm{s}]$ & $E I\left[\mathrm{Nm}^{2}\right]$ & $\mu[24]$ \\
\hline Rectangular & 2.640 & 0.010 & 0.231 & 1.170 \\
\hline Trapeze & 3.360 & 0.014 & 0.323 & 1.170 \\
\hline Trapeze & 1.920 & 0.011 & 0.185 & 1.170 \\
\hline Rhomboid & 3.120 & 0.018 & 0.295 & 1.170 \\
\hline
\end{tabular}




\section{EXPERIMENTAL DEVELOPMENT}

To experimentally validate the model; a methodology was developed, as shown in Fig. 2. The following points were taken into account in the development of the experimental tests: thin aluminium blades; wind speeds of $10 \mathrm{~m} / \mathrm{s}, 20 \mathrm{~m} / \mathrm{s}$, and $30 \mathrm{~m} / \mathrm{s}$; an Aerolab wind tunnel with the capacity to generate winds of up to $160 \mathrm{~km} / \mathrm{h}$; a hermetic test area of $600 \mathrm{~mm}$ $\times 400 \mathrm{~mm} \times 300 \mathrm{~mm}$, in which aluminium support has been installed to maintain the blade in a vertical position; a \pm 9 g MMA7341L accelerometer installed on the blade tip; a Tektronix TBS 1042 oscilloscope, for monitoring and saving the signal; and, computer equipment for processing the acceleration signals. The physical characteristics and mechanical properties of the experimental blades are shown in Table 3. For the validation of the phenomenon, 20 experimental tests were carried out for each of the aforementioned conditions.

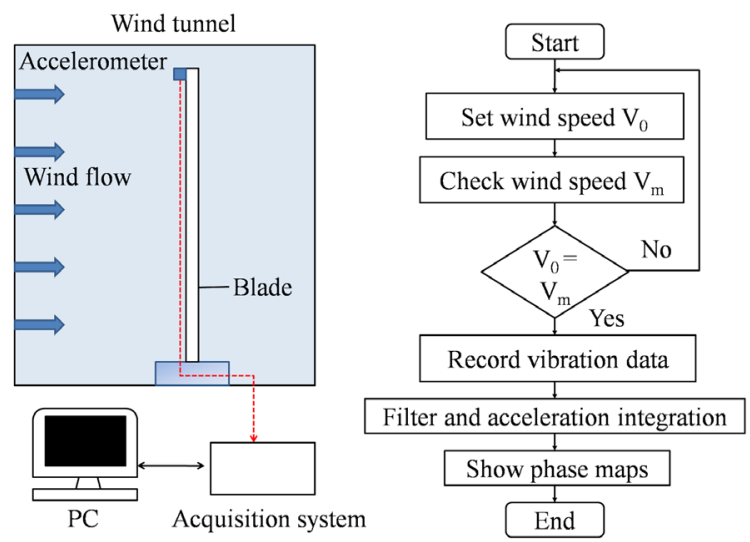

Fig. 2. Experimental schematic and flow diagram for the vibration analysis of the aluminium blades

Table 3. Physical characteristics and mechanical properties of the blades

\begin{tabular}{lcccc}
\hline & \multicolumn{5}{c}{ Blade } \\
\cline { 2 - 5 } & 1 & 2 & 3 & 4 \\
\hline $\begin{array}{c}\text { Geometric } \\
\text { shape }\end{array}$ & $\pi$ & & & \\
& & & & \\
\hline$S\left[\mathrm{E}-3 \mathrm{~m}^{2}\right]$ & 2.540 & 3.360 & 1.920 & 3.120 \\
\hline$C[\mathrm{~kg} / \mathrm{s}]$ & 0.010 & 0.014 & 0.011 & 0.018 \\
\hline$M[\mathrm{~kg}]$ & 0.011 & 0.014 & 0.008 & 0.013 \\
\hline
\end{tabular}

During the experimental tests, the blade was firmly fixed by the lower end. The accelerometer is fixed to the tip of the blade. The front surface of the blade is perpendicular to the wind flow, causing a pressure differential on the surface, resulting in flapwise bending and inducing vibrations. The acceleration signal obtained is integrated using the Simpson rule to define the vibration response of each blade in terms of displacement and speed in a flapwise direction.

\section{RESULTS AND DISCUSSION}

\subsection{Simulation Results}

\subsubsection{Results of the Free Vibration Response}

The numerical results for the dynamic behaviour of the four types of blades are presented in this section. First, the model was solved considering a small displacement $(8 \mathrm{~mm})$ at the free end of the blade as an initial condition, with the results for Blade 1 shown in Fig.3. The frequency spectrum presents a peak at $20 \mathrm{~Hz}$, which corresponds to the first vibration mode. The model was then solved considering a large displacement $(80 \mathrm{~mm})$ at the free end of the blade as an initial condition, with the results compared in Fig. 3. While in Fig. 3a the free movement presents harmonic behaviour, the response is not sinusoidal; instead, it presents harmonic distortion caused by the excitation of the polynomial terms of the equations of motion [28], more notably when the deformation is large. The response shows a decrease over time, behaviour known as a stable system [29]. The frequency spectrum shows the main peak at $16.6 \mathrm{~Hz}$, while the first mode shifts due to non-linear behaviour. Fig. 3b indicates how the nonlinearity effect was particularly pronounced for large deflections. Additionally, the existence of nonlinearities in the system reduced the frequency at which the first mode occurs, which leads to an overall reduction in the stiffness of the dynamic system [27].
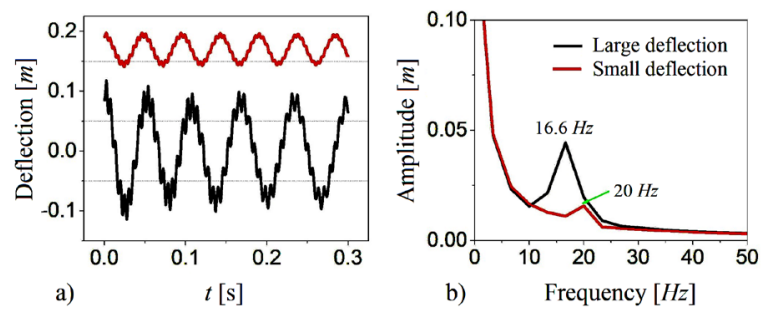

Fig. 3. Comparison of the free movement types (large deflections vs. small deflections for Blade 1; a) response overtime, and b) frequency map

The phase planes represent the instantaneous energy space. The vertical axis corresponds to the kinetic energy and the horizontal axis to the 
potential energy. If the dynamic response is stable, the trajectory described by the energy space will be a smooth function, whereas; if not, the trajectory will display jumps or changes in direction, as well as many internal loops [9]. Fig. 4 presents the phase planes of the dynamic behaviour of Blade 1 in small and large deflections. The phase plane (Fig. 4a) presents closed loops, forming an annular shape, verifying the stable response of the blade to a small displacement value, with, in this case, the diagram showing an elliptical shape [30], thus indicating a linear system. The phase planes presented in Fig. 4b show closed loops with two attracting poles, which remain at the same location at all times. The non-linear effect is notable when this diagram is compared to the linear solution.

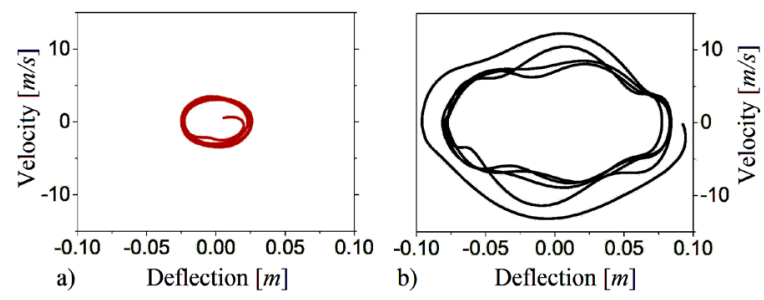

Fig. 4. Phase planes for the free motion of Blade 1: a) small deflection, and b) large deflection

\subsubsection{Results of the Forced Vibration Response}

The phase plane trajectories of motion for different blades are shown in Fig. 5, which illustrates the progression of motion by charting the phase plane plots of velocity $[\mathrm{m} / \mathrm{s}]$ against deflection $[\mathrm{m}]$. The wind speed change values for each column are $10 \mathrm{~m} / \mathrm{s}$, $20 \mathrm{~m} / \mathrm{s}$, and $30 \mathrm{~m} / \mathrm{s}$, from left to right.

Phase plane trajectories are an effective criterion for evaluating both stability and dynamic chaos and are shown for all cases considered in the present study. Blades 1 to 4 , subject to simulated forced vibration at a wind speed of $10 \mathrm{~m} / \mathrm{s}$, present linear dynamic behaviour, characteristics that ensure that the phase planes describe ovoid and regular curves with welldefined cycles, denoting stable dynamic behaviour. However, at higher velocities, the movement curves are found to be influenced by perturbations that cause the dynamic system to be unstable and can be seen in the phase planes, which present amorphous lines that cross over each other and distort the elliptical shape of the dynamic behaviour, leading to an unstable system.

With a wind speed of $20 \mathrm{~m} / \mathrm{s}$, the blades present moderate distortions in their movement curve; therefore, their vibratory response is semi-stable with slight dynamic chaos, the degree of deformation of the oval cycle determining the level of instability. Blade 3 shows a non-linear condition related to a low level of stiffness and amplitude damping [9]. The simulation at $30 \mathrm{~m} / \mathrm{s}$ reveals that the dynamic of the blades is highly unstable with amorphous cycles of great amplitude; the oscillation of the system is chaotic [29]. In the three stages of excitation, Blade 2 shows a tendency for stability, through uniform cycles of movement due to the greater level of stiffness and damping, while Blade1 is susceptible to a state of chaos.
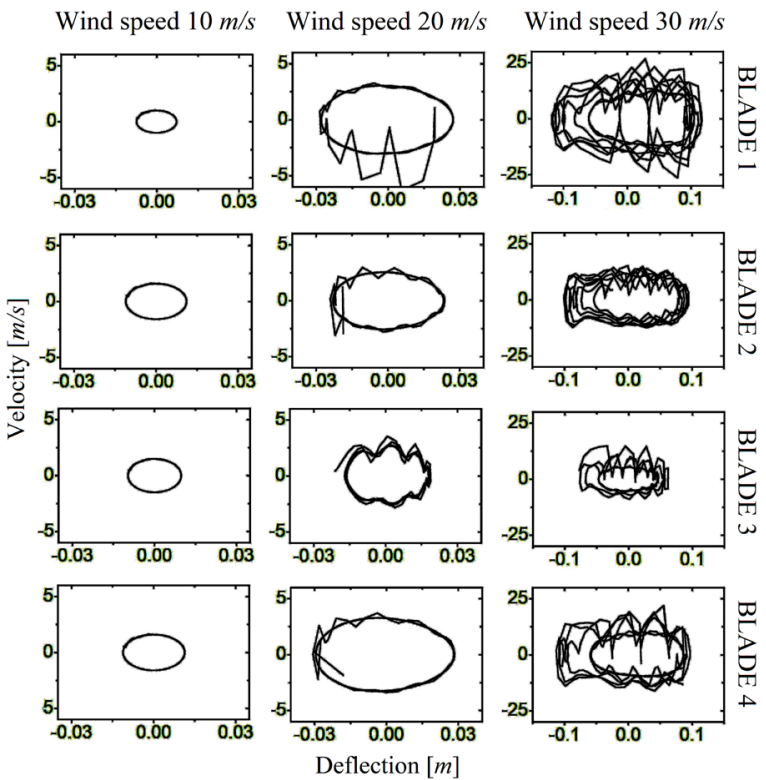

Fig. 5. Phase planes for the dynamic response of the wind turbine blades, under wind excitation of $10 \mathrm{~m} / \mathrm{s}, 20 \mathrm{~m} / \mathrm{s}$ and $30 \mathrm{~m} / \mathrm{s}$

Table 4 presents a comparison of the dominant frequencies of each blade under maximum tip deflection conditions, from which it can be observed that, in forced movement, a decrease in frequency results in increased amplitude, while the opposite effect is seen when the frequency increases, a characteristic of nonlinearity [13].

Table 4. Comparative of simulated results, in free and forced condition at $10 \mathrm{~m} / \mathrm{s}, 20 \mathrm{~m} / \mathrm{s}$, and $30 \mathrm{~m} / \mathrm{s}$

\begin{tabular}{ccccccccc}
\hline \multirow{2}{*}{ Blade } & \multicolumn{2}{c}{ Free } & \multicolumn{2}{c}{$10 \mathrm{~m} / \mathrm{s}$} & \multicolumn{2}{c}{$20 \mathrm{~m} / \mathrm{s}$} & \multicolumn{2}{c}{$30 \mathrm{~m} / \mathrm{s}$} \\
\cline { 2 - 9 } & $f[\mathrm{~Hz}]$ & $\xi[\mathrm{m}]$ & $f[\mathrm{~Hz}]$ & $\xi[\mathrm{m}]$ & $f[\mathrm{~Hz}]$ & $\xi[\mathrm{m}]$ & $f[\mathrm{~Hz}]$ & $\xi[\mathrm{m}]$ \\
\hline 1 & 21.22 & 0.029 & 22.40 & 0.007 & 19.00 & 0.027 & 22.63 & 0.117 \\
\hline 2 & 21.42 & 0.029 & 22.60 & 0.011 & 19.02 & 0.023 & 19.30 & 0.094 \\
\hline 3 & 24.31 & 0.029 & 25.80 & 0.009 & 19.00 & 0.018 & 16.17 & 0.061 \\
\hline 4 & 21.28 & 0.029 & 22.70 & 0.011 & 19.20 & 0.028 & 19.40 & 0.096 \\
\hline
\end{tabular}

\subsection{Experimental Results}

The blades are tested during free movement with a large initial displacement, corresponding to $30 \%$ 
of its length. The non-linear response obtained is shown in Fig. 6, while the time response is shown in Fig. 6a, with the blades presenting approximate sinusoidal behaviour and amplitude decreases over time. Under this condition, the vibrations of the blades are damped, and no instability was observed [31]. The non-linear frequencies that govern the movement of the four blades can be seen in Fig. 6b, which presents results revealing that the harmonic dominating the displacement corresponds to the nonlinear frequencies of the blades. The lowest frequency of $11.97 \mathrm{~Hz}$ corresponds to the blade with the greatest rigidity, while Blade 3 , the most slender of the blades, has a peak at $15.96 \mathrm{~Hz}$ with large amplitude.

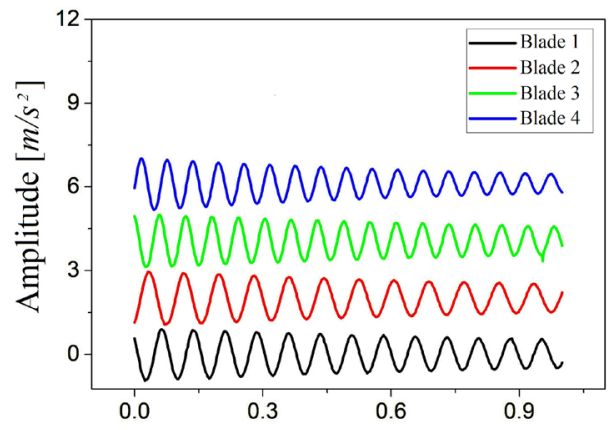

a) $t[\mathrm{~m} / \mathrm{s}]$

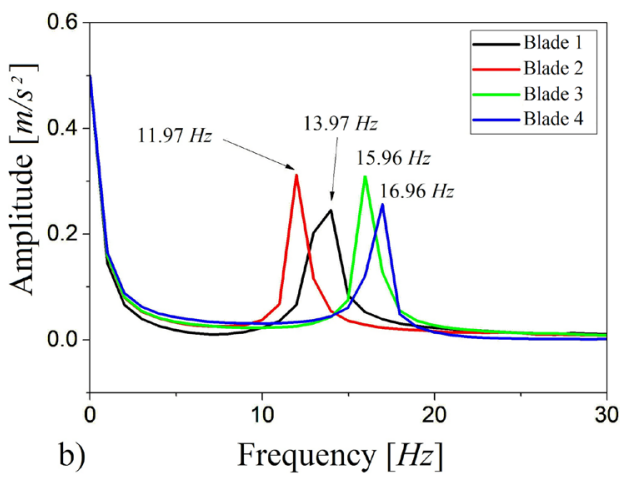

Fig. 6. Comparison of the free movement of the four blades: a) response over time; and, b) frequency map

The results of the forced vibration tests are shown in the phase planes detailed in Fig. 7. These phase planes present the dynamic behaviour qualitatively, highlighting the evolution of the system from stable to unstable as a consequence of the increased wind velocity, which demonstrates how, at velocities of 10 $\mathrm{m} / \mathrm{s}$, the system is harmonious and sinusoidal. This means that the oscillation of the system is proportional between displacement and velocity. This behaviour describes completely elliptical well-defined cycles, with regular circumferences that determine the stability of the oscillation. These phase planes provide information on the blade oscillations, indicating that the greater the magnitude of the vibration associated with the size of the phase cycles, the more pronounced the curves of the ellipse or cycles. Moreover, they maintain a proportional relationship between their velocity and deflection.
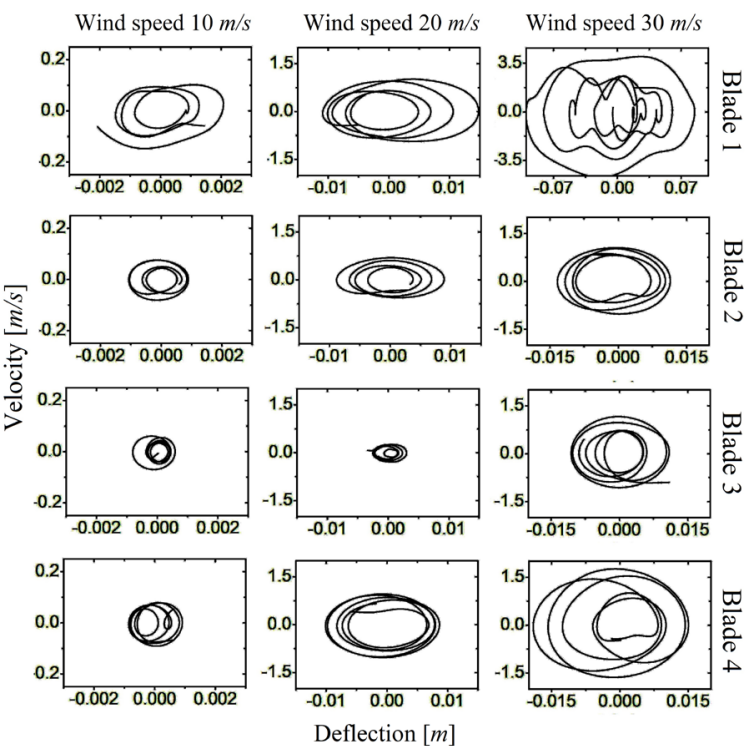

Fig. 7. Velocity-displacement phase planes for the dynamic behaviour of the experimental blades

The phase planes for the blades subjected to a wind flow of $20 \mathrm{~m} / \mathrm{s}$ present dimension increase in comparison with those obtained at $10 \mathrm{~m} / \mathrm{s}$. In general, the phase planes for all the blades show a variation in amplitude and the appearance of ripples, indicating that the dynamic system has evolved despite its semistable behaviour. For example, Blade 1 presents the greatest variation in amplitude, followed by Blade 2, while Blade 3 presents reduced amplitude but high instability. The geometric nonlinearity terms generate an increase in the natural frequencies, which justify the reduced displacement [13], shown in Fig. 8, in which Blade 3 presents an increased frequency when the wind speed increases from $10 \mathrm{~m} / \mathrm{s}$ to $20 \mathrm{~m} / \mathrm{s}$.

In contrast, those blades subjected to a wind flow of $30 \mathrm{~m} / \mathrm{s}$ show larger curves in the phase planes with a drastically distorted elliptical shape. These changes indicate instability in the dynamic behaviour of the blades. In other words, the more amorphous and irregular the phase planes, the more unstable the dynamic response will be. Another critical parameter is the geometric shape, with the trapezoidal shape of Blade 2 giving it greater rigidity and, during the tests, 
balances between stability and the degree of vibration. However, Blade 3, which is very thin, presents a level of instability in the presence of vibrations and large deflections.

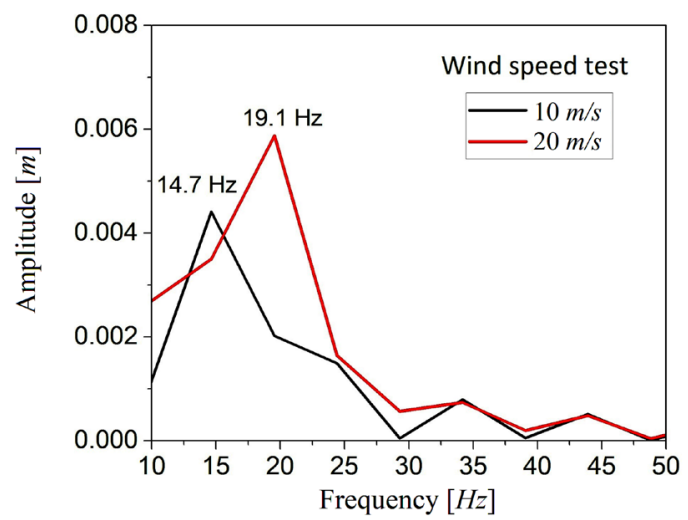

Fig. 8. Evolution of the frequency of Blade 3 in forced motion and excited at $10 \mathrm{~m} / \mathrm{s}$ and $20 \mathrm{~m} / \mathrm{s}$ wind speed

The instability of the vibrations of the blades is attributed to various factors, such as increased wind velocity, geometric nonlinearity, large deflections, elevated amplitudes of vibration and increased pressure on the blade surface, which varies according to the square of the fluid velocity. Rafiee et al. [31] identified four issues that increase the risk of instability in wind turbine blades, two of which are increased aerodynamic force and a low stiffness level.

Table 5. Instability of the dynamic behaviour of the blades analysed

\begin{tabular}{lcccc}
\hline Condition & Blade 1 & Blade 2 & Blade 3 & Blade 4 \\
\hline $0 \mathrm{~m} / \mathrm{s}$ & Stable & Stable & Stable & Stable \\
\hline $10 \mathrm{~m} / \mathrm{s}$ & Stable & Stable & Stable & Stable \\
\hline $20 \mathrm{~m} / \mathrm{s}$ & Semi-stable & Semi-stable & Unstable & Semi-stable \\
\hline $30 \mathrm{~m} / \mathrm{s}$ & Unstable & Semi-stable & Unstable & Unstable \\
\hline
\end{tabular}

Table 5 presents a summary of the degree of stability torsional of the dynamic behaviour of the four blades, as subjected to the different wind velocities. The existing correlation between the experimental and numerical results validates the mathematical model and experimental validation, demonstrating significant convergence and similarity.

\section{CONCLUSIONS}

Developed with polynomial terms, the non-linear model enables the dynamic behaviour of the wind turbine blades to be ascertained, taking into account wind flow velocities, geometric nonlinearity, large deflections, structural damping, and increased wind speed.

The experimental results show particular frequencies of $13.97 \mathrm{~Hz}, 11.97 \mathrm{~Hz}, 17.96 \mathrm{~Hz}$, and $16.96 \mathrm{~Hz}$, which correspond to each of the blades and are related to the non-linear terms of each one. Thus, these frequencies are associated with the effect of large deformations. When Blade 3 is excited at a wind speed of $10 \mathrm{~m} / \mathrm{s}$ to $20 \mathrm{~m} / \mathrm{s}$, the frequency increases from $14.7 \mathrm{~Hz}$ to $19.1 \mathrm{~Hz}$, causing a decrease in the amplitude of movement. Non-linear behaviour, however, is more notable.

The results for both the simulation of the model and the experiments undertaken in the present study confirm that blade stiffness and wind speed are parameters with significant influence on the instability of dynamic behaviour. For example, those blades presenting a lower level of stiffness, such as Blade 1 , with a stiffness of $0.231 \mathrm{Nm}^{2}$, and Blade 3, with a stiffness of $0.185 \mathrm{Nm}^{2}$, are highly unstable, as demonstrated by their amorphous and irregular phase plane curves.

The simulation of the non-linear model represents an economical and fast option for detecting the dynamic behaviour of aeroelastic blade designs under two different operating conditions.

Phase planes are an effective tool for identifying dynamic blade behaviour and can be used to reveal the evolution of the dynamic system from a stable, semistable, unstable and, even, chaotic state.

Consequently, this work can be extended to include, in the modelling, the sectional properties of composite materials, the fluctuating effect of aerodynamic forces, and the rotational effects.

\section{ACKNOWLEDGEMENTS}

This work was supported by the CONACyT under Grant 340392.

\section{NOMENCLATURE}

$x, y, z \quad$ system coordinates, [-]

$\xi, \dot{\xi}, \ddot{\xi}$ deflection out plane, $1^{\text {st }}$ and $2^{\text {nd }}$ derivative time, $\left[\mathrm{m}, \mathrm{m} / \mathrm{s}, \mathrm{m} / \mathrm{s}^{2}\right]$

$\theta, \dot{\theta}, \ddot{\theta} \quad$ deflection slope, $1^{\text {st }}$ and $2^{\text {nd }}$ derivative time, $\left[\mathrm{rad}, \mathrm{rad} / \mathrm{s}, \mathrm{rad} / \mathrm{s}^{2}\right]$

$N_{i} \quad i^{\text {th }}$ function form, [-]

$N_{i} \quad i^{\text {th }}$ deflection coefficient, [-]

$L \quad$ length of blade, [m]

$\rho \quad$ blade density, $\left[\mathrm{kg} / \mathrm{m}^{3}\right]$

$A \quad$ cross section area, $\left[\mathrm{m}^{2}\right]$

$T \quad$ kinetic energy, $[\mathrm{J}]$ 
potential energy, $[\mathrm{J}]$

modulus of elasticity, [N/m²]

moment of inertia, $\left[\mathrm{m}^{4}\right]$

deflection curvature, $[\mathrm{m}]$

instant wind pressure, $\left[\mathrm{N} / \mathrm{m}^{2}\right]$

average wind pressure, $\left[\mathrm{N} / \mathrm{m}^{2}\right]$

fluctuating wind pressure, $\left[\mathrm{N} / \mathrm{m}^{2}\right]$

average wind speed, $[\mathrm{m} / \mathrm{s}]$

fluctuating wind speed, $[\mathrm{m} / \mathrm{s}]$

initial wind speed, $[\mathrm{m} / \mathrm{s}]$

wind speed, $[\mathrm{m} / \mathrm{s}]$

distributed wind force, $[\mathrm{N} / \mathrm{m}]$

wind force respect to $\xi$, [N]

wind force respect to $\theta,[\mathrm{N}]$

air density, $\left[\mathrm{kg} / \mathrm{m}^{3}\right]$

shape coefficient, [-]

dissipative energy, [j]

damping force, $[\mathrm{N}]$

damping force respect to $\theta,[\mathrm{N}]$

damping force respect to $\xi$, [N]

$i^{\text {th }}$ non potential force, $[\mathrm{N}]$

potential force respect to $\xi,[\mathrm{N}]$

potential force respect to $\theta$, [Nm]

damping coefficient, $[\mathrm{kg} / \mathrm{s}]$

blade mass, $[\mathrm{kg}]$

blade surface, $\left[\mathrm{m}^{2}\right]$

fundamental frequency, $[\mathrm{Hz}]$

\section{REFERENCES}

[1] Global Wind Energy Council (2017). Global Wind Statistics, from https://gwec.net/wpcontent/uploads/vip/GWEC_ PRstats2017_EN-003_FINAL.pdf, accessed on 20-03-2020.

[2] Amirat, Y., Benbouzid, M.E.H., Al-Ahmar, E., Bensaker, B., Turri, S. (2009). A brief status on condition monitoring and fault diagnosis in wind energy conversion systems. Renewable and Sustainable Energy Reviews, vol. 13, no. 9, p. 2629-2636, DOI:10.1016/j.rser.2009.06.031.

[3] Savin, A., Iftimie, N., Steigmann, R., Rosu, D., Dobrescu, G., Grum, J., Barsanescu, P. (2018). Effective methods for structural health monitoring of critical zones of scalable wind turbine blades. Strojniški vestnik - Journal of Mechanical Engineering, vol. 64. no. 11, p. 680-689, Dol:10.5545/svjme.2017.5130.

[4] Ju, D., Sun, Q. (2017). Modeling of a wind turbine rotor blade system. Journal of Vibration and Acoustics, vol. 139, no. 5, p. 051013, DOI:10.1115/1.4036633.

[5] Otero, A.D., Ponta, F.L. (2010). Structural analysis of windturbine blades by a generalized Timoshenko beam model. Journal of Solar Energy Engineering, vol. 132, no. 1, p. 011015, Dol:10.1115/1.4000596.

[6] Arrigan, J., Pakrashi, V., Basu, B., Nagarajaiah, S. (2011). Control of flapwise vibrations in wind turbine blades using semi-active tuned mass dampers. Structural Control Health Monitoring, vol. 18, no. 8, p. 840-851, D0l:10.1002/stc.404.
[7] Jokar, H.,Mahzoon, M., Vatankhah, R. (2020). Dynamic modeling and free vibration analysis of horizontal axis wind turbine blades in the flapwise direction. Renewable Energy, vol. 146, p. 1818-1832, D0l:10.1016/j.renene.2019.07.131.

[8] Xu, J., Zhang, L., Li, X., Li, S., Yang, K. (2020). A study of dynamic response of a wind turbine blade based on the multibody dynamics method. Renewable Energy, vol. 155, p. 358368, Dol:10.1016/j.renene.2020.03.103.

[9] González-Cruz, C.A., Jauregui-Correa, C.J., Herrera-Ruiz, G. (2016). Non-linear response of cantilever beams due to large geometric Deformations: Experimental validation. Strojniški vestnik - Journal of Mechanical Engineering, vol. 62, no. 3, p. 187-196, Dol:10.5545/sv-jme.2015.2964.

[10] Ramakrishnan, V., Feeny, B.F. (2011). In-plane non-linear dynamics of wind turbine blades. Proceedings of the ASME International Design Engineering Technical Conferences, vol. 1, p. 761-769, DOI:10.1115/DETC2011-48219.

[11] Inoue, T., Ishida, Y., Kiyohara, T. (2012). Non-linear vibration analysis of the wind turbine blade (Occurrence of the superharmonic resonance in the out of plane vibration of the elastic blade). Journal of Vibration and Acoustics, vol. 134, no. 3, p. 0310091-031913, DOI:10.1115/1.4005829.

[12] Gerstmayr, J., Irschik, H. (2008). On the correct representation of bending and axial deformation in the absolute nodal coordinate formulation with an elastic line approach. Journal of Sound and Vibration, vol. 318, no. 3, p. 461-487, DOI:10.1016/j.jsv.2008.04.019.

[13] Maktouf, R., Yangui, M., Fakhfekh, T., Nasri, R. Haddar, M. (2019). Non-linear dynamic analysis of a wind turbine blade. Journal of the Chinese Institute of Engineers, vol. 42, no. 8, p. 727-737, DOI:10.1080/02533839.2019.1660229.

[14] Liu, W.Y. (2013). The vibration analysis of wind turbine bladecabin-tower coupling system. Engineering Structures, vol. 56, p. 954-957, DOI:10.1016/j.engstruct.2013.06.008.

[15] Madsen, H.Aa., Bak, C., Døssing, M., Mikkelsen, R., Øye, S. (2010). Validation and modification of the Blade Element Momentum theory based on comparisons with actuator disc simulations. Wind Energy, vol. 13, no. 4, p. 373-389, DOl:10.1002/we.359.

[16] Wang, L., Liu, X., Kolios, A. (2016). State of the art in the aeroelasticity of wind turbine blades: Aeroelastic modelling. Renewable and Sustainable Energy Reviews, vol. 64, p. 195210, D0I:10.1016/j.rser.2016.06.007.

[17] Utsch de Freitas Pinto, R.L., Furtado Gonçalves, B.P. (2017). A revised theoretical analysis of aerodynamic optimization of horizontal-axis wind turbines based on BEM theory. Renewable Energy, vol. 105, p. 625-636, D0I:10.1016/j. renene.2016.12.076.

[18] Akbiyik, H., Yavuz, H., Akansu, Y. (2018). A study on the plasma actuator electrode geometry configurations for improvement of the aerodynamic performance of an airfoil. Strojniški vestnik - Journal of Mechanical Engineering, vol. 64, no. 12, p. 719-725, DOl:10.5545/sv-jme.2017.5041.

[19] Wang, G.-X., Ding, H., Chen, L.-Q. (2020). Gravitational effects and mode interactions of vertical cantilever beams. International Journal of Non-linear Mechanics, vol. 123, p. 103493, Dol:10.1016/j.jijnonlinmec.2020.103493. 
[20] Domagalski, L. (2018). Free and forced large amplitude vibrations of periodically inhomogeneous slender beams. Archives of Civil and Mechanical Engineering, vol. 18, no. 4, p. 1506-1519, D0l:10.1016/j.acme.2018.06.005.

[21] Jin, X., Liu, H., Ju, W. (2014). Wind turbine seismic load analysis based on numerical calculation. Strojniški vestnik - Journal of Mechanical Engineering, vol. 60, no. 10, p. 638648, D0l:10.5545/sv-jme.2014.1646.

[22] Tang, A.-Y., Li, X.-F., Wu, J.-X., Lee,K.Y. (2015). Flapwise bending vibration of rotating tapered Rayleigh cantilever beams. Journal of Constructional Steel Research, vol. 112, p. 1-9, DOl:10.1016/j.jcsr.2015.04.010.

[23] Li, L., Zhang, X., Li, Y. (2016). Analysis of coupled vibration characteristics of wind turbine blade based on green's functions. Acta Mechanica Solida Sinica, vol. 29, no. 6, p. 620-630, D0l:10.1016/S0894-9166(16)30332-9.

[24] Damaren, C., Sharf, I. (1995). Simulation of flexible-link manipulators with inertial and geometric nonlinearities. Journal of Dynamic Systems, Measurement, and Control, vol. 117, no. 1, p. 74-87, D0l:10.1115/1.2798525.

[25] Martins, J., Ayala Botto, M. Sá da Costa, J. (2002). Modeling of flexible beams for robotic manipulators. Multibody System Dynamics, vol. 7, p. 79-100, Dol:10.1023/A:1015239604152.

[26] Bai, Y., Jin, W.-L. (2016). Chapter 6 - Wind loads for offshore structures. Marine Structural Design (Second
Edition), Butterworth-Heinemann, Amsterdam, p. 95-118, D0I:10.1016/B978-0-08-099997-5.00006-X.

[27] O'Brien, J.M., Young, T.M., O'Mahoney, D.C., Griffin, P.C. (2017). Horizontal axis wind turbine research: A review of commercial CFD, FE codes and experimental practices. Progress in Aerospace Sciences, vol. 92, p. 1-24, D0I:10.1016/j. paerosci.2017.05.001.

[28] Larsen, J. W., Nielsen, S. R. K. (2007). Non-linear parametric instability of wind turbine wings. Journal of Sound and Vibration, vol. 299, no. 1-2, p. 64-82, D0l:10.1016/j. jsv.2006.06.055.

[29] Sayed, M., Kamel, M. (2011). Stability study and control of helicopter blade flapping vibrations. Applied Mathematical Modelling, vol. 35, no. 6, p. 2820-2837, D0l:10.1016/j. apm.2010.12.002.

[30] Leung, A.Y.T., Mao,S.G. (1995). A symplectic Galerkin method for non-linear vibration of beams and plates. Journal of Sound and Vibration, vol. 183, no. 3, p. 475-491, D0l:10.1006/ jsvi.1995.0266.

[31] Rafiee, R., Tahani, M., Moradi, M. (2016). Simulation of aeroelastic behavior in a composite wind turbine blade. Journal of Wind Engineering and Industrial Aerodynamics, vol. 151, p. 60-69, D0l:10.1016/j.jweia.2016.01.010. 